\title{
JG|U
}

Gutenberg School of Management and Economics \& Research Unit "Interdisciplinary Public Policy" Discussion Paper Series

\section{Monetary and non-monetary incentives for educational attainment:}

\section{Design and effectiveness}

Hannah Schildberg-Hörisch, Valentin Wagner

November 23, 2018

\section{Discussion paper number 1821}


Hannah Schildberg-Hörisch

Düsseldorf Institute for Competition Economics (DICE)

Heinrich-Heine-Universität Düsseldorf

Universitätsstr. 1

40225 Düsseldorf

Germany

schildberg-hoerisch@dice.uniduesseldorf.de

\author{
Valentin Wagner \\ Chair of Public and Behavioral Economics \\ Gutenberg School of Management and Economics \\ University of Mainz \\ Jakob-Welder-Weg 4 \\ 55128 Mainz \\ Germany
}

wagner@uni-mainz.de

All discussion papers can be downloaded from http://wiwi.uni-mainz.de/DP 


\section{Monetary and non-monetary incentives for educational attainment:}

\section{Design and effectiveness}

\section{Hannah Schildberg-Hörisch* and Valentin Wagner $^{\dagger}$}

November 23, 2018

Keywords: monetary and non-monetary incentives, design of incentive schemes, educational attainment JEL Code: I20

\section{Introduction}

The use of extrinsic incentives to steer individual behavior is at the heart of economics. The "basic law of behavior" is that higher incentives will lead to higher levels of effort provision (Gneezy et al., 2011). Education is one area in which regular provision of effort is key in order to realize large returns (Oreopoulos, 2007). The returns to education do not only encompass higher levels of human capital and higher wages (Angrist and Keueger, 1991), but also various positive externalities of education such as reduced crime (Lochner and Moretti, 2004) and teenage pregnancy (Black et al., 2008), better health (Lleras-Muney, 2005), higher political involvement (Milligan et al., 2004), and higher levels of productivity and growth of GDP per capita for a country as a whole (Hanushek and Wößmann, 2012).

However, students often invest too little in their own education and drop out of school too early, given that, according to the standard framework of the education production function, investments in education should reflect the discounted returns to schooling net of costs (Sadoff, 2014). Many of the tasks students perform in school (e.g., homework assignments) yield benefits only in the far future. Thus, time-inconsistent preferences (Bettinger and Slonim, 2007), or neglect of positive externalities may induce students to make sub-optimal investment decisions in education. Extrinsic incentives for educational inputs or outputs can possibly tackle these sub-optimal investment decisions by offering immediate rewards to students. If students lack sufficient motivation, strongly discount the future, or have inaccurate information on the returns to education, immediate rewards can increase students' performance in education (Fryer, 2011). ${ }^{1}$

In principle, extrinsic incentives can be of monetary or non-monetary nature. The effects of monetary incentives for students, parents, and teachers on educational attainment have been studied widely. However,

\footnotetext{
*Hannah Schildberg-Hörisch: Düsseldorf Institute for Competition Economics (DICE), schildberg-hoerisch@dice.uniduesseldorf.de

†Valentin Wagner: University of Mainz, Germany, wagnerv@uni-mainz.de

${ }^{1}$ Fryer (2011) also argues though that extrinsic incentives have little impact on performance if students lack resources or knowledge to convert effort into achievement or if the production function has important complementarities out of their control. Moreover, extrinsic incentives may have negative effects on education outcomes in case they undermine intrinsic motivation.
} 
the use of monetary incentives may be difficult to scale up because they are potentially expensive and educators and parents may be skeptical about "cash for grades". Non-monetary incentives have the potential to mitigate these problems while being cost-effective in increasing educational attainment. A growing number of academic research therefore evaluates the effectiveness of non-monetary incentives, in particular among younger children who might be more responsive to non-monentary incentives than older children (Levitt et al., 2016a). Moreover, enhancing the motivation of young children to invest in their education by providing extrinsic incentives early on is considered especially effective due to self-productivity and dynamic complementarity of skills in the process of skill formation over time (Cunha and Heckman, 2007).

This paper reviews the literature on providing extrinsic, monetary and non-monetary incentives to increase educational attainment. Thereby, we focus on the design and implementation of extrinsic incentives in the field. We cover financial incentives only in brief, focusing on the role of cash size and recipient (students, parents, or teachers). We then discuss different types of non-monetary incentives, review which types of incentives are preferred by students if they are free to choose, and report evidence on the effectiveness of non-monetary incentives to raise educational achievement, mainly in primary and secondary education.

\section{Monetary incentives}

For economists, extrinsic financial incentives are a "natural way" to motivate individuals. Different types of financial incentives have been tested so far, e.g., cash for grades, end of year prizes, cash for attendance and enrollment, tuition fee wavers, and teacher merit pay. Gneezy et al. (2011) summarize the empirical evidence on the effectiveness of financial incentives from large-scale field experiments as follows: (i) financial incentives work well in increasing attendance and enrollment, (ii) financial incentives have mixed results regarding effort provision and achievements, and (iii) financial incentives seem to work for some students, but not for others.

Since our focus lies on the design of extrinsic incentive schemes, we proceed by discussing whether and how the effectiveness of monetary incentives relates to variations in cash size or recipient of monetary incentives.

\section{Sensitivity to cash size}

Standard economic theory predicts that higher cash incentives lead to greater effort and higher educational outcomes. $^{2}$ Leuven et al. (2010), De Paola et al. (2012), and Barrow and Rouse (2018) test this prediction among university students by varying the amount of money that students can earn. Leuven et al. (2010) and De Paola et al. (2012) offer incentives of similar magnitude. In Leuven et al. (2010), students earn €681 in the high incentive treatment and $€ 227$ in the low incentive treatment if they collect all possible credit points for the first year within one year. De Paola et al. (2012) use a rank-based incentive scheme in which only the 30 best-performing students (about 19-20 percent of students in the treatment groups) receive either $€ 250$ or $€ 700$. Although the two studies use different incentive schemes (for absolute versus relative performance, respectively), both find a positive effect of financial incentives on the performance of high-ability students only and, on average, no significant difference between the high and low incentive treatments. Barrow and Rouse

\footnotetext{
${ }^{2}$ If students (or parents) maximize utility by balancing marginal benefits from obtaining better educational outcomes and marginal costs from exerting effort, monetary incentives on educational inputs (such as effort provision) or educational outcomes increase their marginal benefits and thus their provision.
} 
(2018) analyze the effects of varying the cash size of The California Scholarship Program. Students receive incentives ranging from $\$ 500$ to $\$ 1000$ per semester, (i) either for meeting the end-of-semester performance benchmark (a final average grade of "C" or better in at least 6 credits) only during fall semesters or (ii) half of the incentive is paid for enrolling for six or more credits and half for meeting the performance benchmark during spring semesters. Based on survey data, Barrow and Rouse (2018) find an overall positive effect of financial incentives on students' time spent on educational activities, their quality of effort, and engagement with their studies (measured by learning strategies, academic self-efficacy, and motivation). However, larger cash incentives do not generate larger increases in time spent on academic activities and effort than smaller incentive payments. In a developing country context, Baird et al. (2011) experimentally investigate both the sensitivity to cash size and the role of the recipient (Malawian parents or adolescent daughters). Enumeration areas are either randomized to one of the treatment conditions and receive cash transfers or to the control group receiving no transfers. Moreover, in the treatment conditions, recipients either receive unconditional or conditional cash transfers, i.e. for 80 percent or above school attendance per month. Cash transfers to parents vary between $\$ 4, \$ 6, \$ 8$, and $\$ 10$ and cash transfers to girls (15-16 years) are $\$ 1, \$ 2, \$ 3, \$ 4$, or $\$ 5$ per month. Overall, conditional cash transfers outperform unconditional ones in terms of schooling outcomes (enrollment, attendance given enrollment, and achievement tests). Increasing transfer amounts has no effect on educational outcomes if they are conditional or paid to girls. Only increasing unconditional cash transfers to parents increases enrollment rates of girls, but seems to decrease their performance in test scores. Using a sample that is largely comprised of low income, minority students, Levitt et al. (2016a) find that second to tenth graders in the U.S. obtain significantly better test scores in low stakes tests if they receive a cash reward of $\$ 20$ for a performance increase compared to their previous test result, but not for a reward of $\$ 10$.

Overall, larger cash rewards for educational inputs or performance do not seem to produce different results than smaller cash rewards among university students. The findings of Levitt et al. (2016a) suggest that younger and / or more disadvantaged students might be more responsive to varying cash size for performance increases. However, more research on the sensitivity to cash size among students of different age groups and backgrounds is needed for more reliable conclusions. A further open question refers to how the context under consideration affects a possible lower limit for financial incentives to become effective.

\section{Recipient}

Students' motivation is a key input for educational attainment and can be influenced by parents, teachers, and peers. When designing financial incentive schemes in education, it is thus critical to know who should be rewarded to raise educational outcomes most (cost-)effectively. Parental inputs such as their attitude toward or involvement at school are important determinants of children's cognitive and non-cognitive skills (Avvisati et al., 2014; Bergman and Chan, 2017; Bergman, 2017; Cunha et al., 2017) and getting parents involved in school seems promising to modify students' behavior. Financial incentives to parents that are conditional on children's educational outcomes provide information to parents and might be effective because they reduce or close information frictions between parents and children. In contrast, unconditional financial incentives contain no informational value for parents. Bursztyn and Coffman (2012), for example, show that parents 
prefer conditional cash transfer programs over unconditional transfers, suggesting that parents desire to reduce information asymmetries between them and their children and seek for methods to help them control their children.

The majority of studies vary the recipient of monetary incentives within the household and find little evidence for a differential impact of offering financial incentives to parents as opposed to their children. Berry (2015) reward either Indian parents or their children with 100 rupees conditional on children's performance increase in a reading test, Baird et al. (2011) provide conditional or unconditional cash transfers to parents or their daughters in Malawi, and de Walque and Valente (2018) investigate the impact of equally sized financial incentives for high attendance rates to either children or their parents in Mozambique. Levitt et al. (2016b) reward either parents or children in Chicago high schools with $\$ 50$ or participation in a lottery with a 10 percent probability of winning $\$ 500$ if children meet monthly, minimum achievement standards for attendance, behavior, grades and test scores. These studies find no evidence that the recipient of the reward impacts educational outcomes, i.e. treatment effects do not differ significantly between treatments that incentivize students and parents. ${ }^{3}$

Behrman et al. (2015) vary whether students or their teachers are eligible to receive financial rewards and additionally investigate an aligned incentive treatment, in which students, teachers, and school administrators simultaneously receive financial rewards contingent on students' performance in an end-of-year mathematics test. The authors find no effect on students' performance if only teachers receive incentives. However, incentivizing only students yields positive and significant effects on math performance and aligning incentives produces even larger effects. Fryer et al. (2017) test aligned, simultaneous incentives to students, parents, and teachers only. Students and their parents receive $\$ 2$ each for each math assignment mastered (answering at least four out of five questions correctly) by the students, parents are additionally paid $\$ 20$ for each parent-teacher review session they attend, and teachers receive $\$ 6$ for each academic conference held with a parent plus possibly high performance bonuses for students' achievements on standardized tests. While Fryer et al. (2017) find large and significant positive treatment effects on incentivized achievements in math, achievements in reading, which are not incentivized, decrease significantly. In contrast, List et al. (2018) find no significant effects of aligning incentives of students, parents, and teachers. They pay either students and their parents $\$ 45$ each or students, parents, and teachers $\$ 30$ each if a student meets predefined standards (improvement of test scores, maintaining course grades, and avoidance of unexcused absences and suspensions). In three further treatments, List et al. (2018) test three individual incentive schemes in which they either pay students, parents, or teachers $\$ 90$. Their findings in the individual treatments are in line with the aforementioned literature (Berry, 2015; Baird et al., 2011; Levitt et al., 2016b) - treatment effects are positive, large and significant (0.30-0.37 standard deviations) and sign and significance of the treatment effects do not change regardless of who receives the reward.

Overall, the recipient of financial incentives (students, parents, or teachers) does not seem to make a dif-

\footnotetext{
${ }^{3}$ The treatment effects per se are typically positive. Berry (2015) does not have a randomized control group, but comparing his experimental results to a quasi-experimental control group suggests that incentives substantially improve test scores. Baird et al. (2011) find that both conditional and unconditional cash transfers tend to increase school enrollment, while tests scores increase for conditional transfers only. In de Walque and Valente (2018), incentives to both children and parents are effective in increasing attendance rates, with a 38 percent, but not significantly larger effect for incentivizing children than parents. Levitt et al. (2016b) find positive and significant treatment effects which are modest in size.
} 
ference for their effectiveness. The so far limited research on aligning student, parent, and teacher incentives shows promising results in terms of increasing students' educational achievements even further, but the existing evidence is not completely equivocal.

\section{Non-monetary incentives}

Whether non-monetary incentives can affect students' educational attainment as well has recently received increasing attention in the economics of education literature. When providing non-monetary incentives to students, researchers first have to identify and choose appropriate non-monetary incentives before they can assess their impact on educational attainment. So far, little is known about students' valuation of different types of non-monetary incentives. We therefore first propose a categorization of non-monetary incentives which is based on Wagner and Riener (2015). We then review studies reporting students' incentive choice and summarize the literature examining the effectiveness of non-monetary incentives on students' educational attainment.

\section{Types of non-monetary incentives}

Non-monetary incentives for students can be broadly categorized into (providing) tangible non-monetary incentives on the one hand and granting rights and privileges on the other hand. Tangible non-monetary incentives comprise trophies, certificates, candies, or toys, for example. Non-monetary incentives in the category granting rights and privileges are mostly non-tangible (although they might be given in the form of a voucher) and grant students privileges such as getting out of one homework assignment or having the privilege to go off campus during the school day. Incentives such as bonus points for the next exam also fall into this category, as they can be interpreted as a privilege to start the exam with a lead compared to others.

Wagner and Riener (2015) propose to further subdivide the above mentioned two main categories: (i) "mastery goal incentives", (ii) "social recognition incentives", and (iii) "curiosity incentives" are classified as tangible non-monetary incentives, (iv) "work avoidance incentives", and (v) "consumption rights" as granting rights and privileges. 4 We further add the sub-category "toys and candies" to the tangible non-monetary incentives as many studies use this kind of rewards. Table 1 gives an overview about the two main categories, their sub-categories and examples of experimental studies.

Mastery goal incentives support the joy of learning and the motivation to expand knowledge in one subject. Hence, this category mainly consists of incentives which constitute educational inputs such as books and science kits. Social recognition incentives acknowledge students' achievements either in private or in public. Curiosity incentives could be any type of non-monetary incentives but, importantly, students do not know ex ante what exactly the incentive is. As indicated by their name, toys and candies incentives are incentives students can play with or eat. Work avoidance incentives compensate students for their past educational investments in the future, e.g., by giving them extra points in the next exam or reducing the work load of their homework. Consumption rights give students the right to do something which is usually forbidden in school (e.g., using the cell phone during class) or determined by the teacher (e.g., choose games in the physical educational lesson).

\footnotetext{
${ }^{4}$ These categories are mainly motivated by the concept of Goal Theory, a widely used concept in pedagogical research (see Ames, 1992).
} 


\section{Selection of non-monetary incentives}

So far, most studies have offered predetermined non-monetary rewards to students without reporting students' perceived valuation of the reward or on which grounds they have chosen the incentive. However, knowing students' perceived valuation is crucial for designing effective incentive schemes. Moreover, if the valuation of various non-monetary incentives differs between students, e.g., by gender or ability, incentive schemes should be tailored to the target audience.

To our knowledge, only Wagner and Riener (2015) report the results of a survey in which they ex ante elicit students' preferences for different non-monetary incentives. Wagner and Riener (2015) survey 241 high school students attending fifth and sixth grades in Germany in the run-up of a field experiment and ask students to name their most preferred incentive among a list of 17 non-monetary incentives. Based on students' answers in this survey, the authors select four non-monetary incentives among which students can choose in the main experiment.

Figure 1 presents the survey results. Overall, students prefer work-avoidance incentives and private social recognition incentives over mastery incentives and public social recognition incentives. The modal choice of students is bonus points for the next exam, followed by homework-voucher and surprise. In their main experiment, Wagner and Riener (2015) use homework-vouchers ${ }^{5}$ and surprise incentives but not bonus points because teachers were not allowed to use them. However, other studies test bonus points and assessment weighting (e.g., the average of one or several graded problem sets or homeworks counts toward the final class grade) among university students (Chevalier et al., 2018; Bigoni et al., 2015; De Paola et al., 2015; Grove and Wasserman, 2006; Emerson and Mencken, 2011) and find positive effects on students' motivation. Granting the right to use the cell phone for 5 minutes during class is another highly ranked incentive (rank 5 out of 17). Since the use of cell phones is strictly prohibited in most German schools, Wagner and Riener (2015) could not test this incentive, but Fryer (2016) does. He rewards students with credits to talk if they read books outside of school and finds no effect on effort or test scores. Notably, students evaluate a letter to parents which is praising the students' performance as valuable (rank 4 out of 17). Students' rather frequent choice of the letter to parents could indicate that students want to sent a positive signal and might want their parents to get involved in their education. This result is especially interesting as recent research shows that getting parents involved in the education of their children is an important input for students' academic careers (Avvisati et al., 2014; Bergman and Chan, 2017; Bergman, 2017; Cunha et al., 2017).

Rewards of the category (public) social recognition-incentives that make students' academic achievements salient to their peers in the classroom, e.g. classroom-picture and classroom-list-are almost never chosen in the survey. Testing a public recognition award, Bursztyn and Jensen (2015) find that performance declines if a leaderboard is installed and sign-up rates for an online SAT preparatory course are lower if students' decisions are made public. Another unpopular reward is a certificate which is awarded privately, although Jalava et al. (2015) find that girls respond strongly to being rewarded with a certificate. It would be interesting to explore in future research whether these stated preferences differ by culture or institutional setting.

\footnotetext{
${ }^{5}$ On request, Levitt et al. (2016a) report that they also tested a homework pass in one school district.
} 
Several further studies give students the opportunity to choose a reward out of a predetermined set of rewards during the experiment (Berry, 2015; Guryan et al., 2016; Burgess et al., 2016; de Walque and Valente, $2018)^{6}$, but do not conduct or report results of a pre-survey. Only Guryan et al. (2016) and Wagner and Riener (2015) provide detailed information on students' incentive choices. In Guryan et al. (2016), students receive points for reading books which can be exchanged for various toys (e.g., a razor scooter, an interactive robot toy, a watercolor paint, and easel set), or combinations of prizes. 25 percent of students who receive points do not claim a prize and students claiming a prize are significantly more likely to choose non-book prizes than book prizes (mastery goal incentive), at a ratio of approximately 5 to 1 . This is in line with the survey results of Wagner and Riener (2015) that mastery goal incentives seem to be unpopular among students. Wagner and Riener (2015) discuss students' incentive choice among their four predetermined incentives (receiving a medal, a homework-voucher, a letter to parents, or a surprise for grade improvements) in depth. Overall, the surprise reward proves to be very popular and is the modal choice of students - approximately one third of students opt for it. The letter to parents (27 percent), the homework-voucher ( 21 percent) and the medal (20 percent) seem to be similarly popular. With respect to school type-schools preparing for the academic track or vocational training — and gender, the authors do not find notable differences in students' incentive choice, except that boys are slightly more likely to choose the medal, while girls more often go for the surprise. Furthermore, the authors distinguish students by ability based on their past midterm grade in math. The surprise incentive is popular for all ability levels, but low ability students choose the letter to parents significantly more often than high ability students. Only 8 percent of high ability students chose the letter to parents, 32 percent the medal, and 26 percent the homework-voucher. In contrast, 42 precent of low ability students chose the letter to parents, 10 percent the medal, and 16 percent the homework-voucher.

These results indicate a heterogeneous valuation of non-monetary incentives by students' ability and that the target audience (peers or parents) of the signaling value of non-monetary incentives might play a crucial role for their effectiveness (as indicated by Bursztyn and Jensen, 2015).

\section{Effectiveness of non-monetary incentives}

Non-monetary incentives for students

Non-monetary incentives for students have been studied to a larger extent than non-monetary incentives for parents or teachers. Table 2 gives an overview of the relevant literature and highlights differences in the design of incentive schemes with respect to subjects' age, stakes of the test, incentives offered, whether incentives were predetermined, and whether they were offered for educational inputs or outputs.

All studies on tangible non-monetary incentives, such as toys, books, trophies, or certificates, have in common that they provide non-monetary incentives in a low stakes testing environment, i.e. for tests that do not count for the final course grade. Non-monetary incentives are either provided for educational inputs or outputs

\footnotetext{
${ }^{6}$ In Berry (2015), students could choose between a cricket set, a doll, a car, or a drawing set or they received (in another treatment arm) a voucher redeemable for a toy in a shop. Girls in the study of de Walque and Valente (2018) get vouchers to buy school uniforms, shoes, school bags, or smaller school materials. de Walque and Valente (2018) report that their incentive selection is based on information gathered during focus group discussions but do not present detailed results of these discussions. In Burgess et al. (2016), students do not choose from a predefined set-but choose the event for a school trip, jointly with the school administration.
} 
and in most studies students cannot choose their incentive. Moreover, tangible non-monetary incentives have been offered predominantly to rather young children (below grade 8). One reason might be that schools are more comfortable rewarding younger students with non-monetary incentives and are therefore more likely to participate in those studies. Furthermore, younger children might be less familiar with cash, might receive higher utility from non-monetary incentives, and might be more likely to overestimate the value of non-financial rewards (Levitt et al., 2016a). Levitt et al. (2016a) compare the effectiveness of a trophy-either framed as a loss or a gain - among elementary school students to middle and secondary school students and find that younger students respond stronger to non-monetary incentives only if they are framed as a loss.

Overall, the effects of tangible non-monetary incentives are mixed: They have either no effect or positively affect students' motivation and performance. These mixed results are prevalent independently of whether incentives reward investments into educational inputs or outputs. Positive results are mostly found for a subsample of students under investigation and results differ in for whom the rewards are motivating. For example, Springer et al. (2015) find that especially girls respond to non-monetary incentives, while Levitt et al. (2016a) find suggestive evidence that boys are more responsive than girls. These heterogeneous findings by gender could be explained by the different non-monetary incentives in place. Girls might be more motivated by a certificate (Springer et al., 2015) than by a trophy (Levitt et al., 2016a). Using non-monetary incentives provided for educational outputs (improvements in literacy), Berry (2015) finds positive effects for low-performing students, while Guryan et al. (2016) incentivize educational inputs (reading books) and tend to find somewhat stronger positive results for already motivated students. Clearly, further research is needed to investigate why the results of these studies differ. Other design features of non-monetary incentives which might be fruitful areas for future research are the timing of non-monetary incentive payments and the effects of repeated incentive payments. We are aware of only one study showing that delayed as opposed to immediate incentive payments are ineffective (Levitt et al., 2016a) and, to our knowledge, no study has investigated the effectiveness of repeated non-monetary incentive payments.

Extrinsic incentives in education are often criticized to crowd out the intrinsic motivation of students permanently leading to lower educational attainment once the incentives are removed. Fryer (2016) examines whether non-monetary incentives crowd out motivation in the ACT college entrance exam four years after students have been incentivized for reading books outside of school-students could earn cell phone minutes which could be used outside of school. Martorell et al. (2016) investigate whether "goody bags" for attendance in a summer-school program have an impact on attendance rates and standardized test scores during the regular school year following the summer program. Levitt et al. (2016a) explore whether a trophy for performance in a low stakes test is detrimental for performance in a test of the same subject months later and Visaria et al. (2016) test the long-term effects of non-monetary incentives (two pencils and an eraser) for attendance in nonformal schools in India. Fryer (2016), Levitt et al. (2016a), and Martorell et al. (2016) find no evidence that tangible non-monetary incentives crowd out intrinsic motivation: there is no or no clear impact on performance or attendance rates after the incentives have been removed. In Visaria et al. (2016), non-monetary incentives increase attendance rates while in place, but have heterogeneous long-run effects for students with high and low 
baseline attendance. Students with low baseline attendance decrease their attendance rate after the removal of the incentive and their performance in a test three months later is lower than if there had been no incentive at all. In contrast, students with high baseline attendance are not affected by the removal of the reward in the long-term.

In contrast to tangible non-monetary incentives, studies using granting rights and privileges as incentives have mainly relied on older students (14-21 years old). Most studies in this category incentivize students' behavior (e.g., test performance, attendance) with bonus points for the next exam or the course grade (Baumert and Demmrich, 2001; Bigoni et al., 2015; Chevalier et al., 2018; De Paola et al., 2015; Emerson and Mencken, 2011; Grove and Wasserman, 2006). We classify these incentives as high stakes since they directly influence students' final course grade or GPA. Besides bonus points, incentives in this category grant rights to students if certain academic performance and/or behavior requirements are fulfilled such as having the right to obtain a driver's license (Barua and Vidal-Fernandez, 2014), qualifying for a high-value event (Burgess et al., 2016), going off campus during the school day (Lichtman-Sadot, 2016), or participating in high school extra curricular sports (Vidal-Fernández, 2011).

Overall, granting rights incentives have positive effects on educational attainment. Barua and VidalFernandez (2014) find that a "No Pass No Drive" law at the state level increases males' additional years of education by 0.064 years and their likelihood to graduate from high school by 1.5 percent, while the effects are not significant for girls. Lichtman-Sadot (2016) report a 0.1 standard deviation increase in test scores if a conditional open campus policy is in place compared to an unconditional policy. Vidal-Fernández (2011) finds a 2 percentage points increase in the likelihood of graduation if student athletes are required to pass one additional course in order to be allowed to participate in school sports. Bonus points or assessment weighting are also effective to motivate students. Grove and Wasserman (2006) document an increase in students' exam performance by one-third to two-thirds of a letter grade if graded problem sets comprise 15 percent of the final grade, Chevalier et al. (2018) estimate the return to a 10 percent assessment weighting to be around 0.27 of a standard deviation in the final in-term examination grade, and Emerson and Mencken (2011) find that if homework counts toward the final course grade, students improve course-specific achievement measures, but do not perform better on standardized tests. Only Baumert and Demmrich (2001) do not find positive effects for students in grade 9 if a test counts toward the final course grade. One reason could be an age effect because students in their sample are much younger than students in the other studies using bonus points or assessment weighting (grade 9 vs. university students). Interestingly, the survey findings of Wagner and Riener (2015) indicate that bonus points are perceived as attractive by even younger children (grades 5 and 6 ) as well. Thus, it would be promising to test bonus points for the next exam among younger children as they are easy and costless to implement and potentially reduce the stress level of students while sitting for an exam.

To summarize, tangible non-monetary incentives have been mostly given to younger children with mixed results: they have been found to either increase or not to change students' motivation and performance. Nonmonetary incentives in the form of granting rights have been analyzed predominantly among (older) high school students, while bonus points and assessment weighting have been analyzed predominantly among university 
students. Both types of incentives have typically produced positive results.

Non-monetary incentives for parents and teachers

The effects of non-monetary incentives for parents on students' educational attainment have been studied rarely. We are aware of only one study testing a social recognition reward. ${ }^{7}$ Mayer et al. (2018) equip parents of children who attend a subsidized preschool with an electronic tablet and a preloaded application with children's books. Parents are asked to read to their children and are incentivized to increase the time using the digital library by a "social recognition reward". Parents receive a private congratulatory message and a cartoon bear does a celebratory dance if parents meet their self-set goal. Further, all treated parents receive a message which tablet number reads the most to their child. Thus, this incentive can be categorized as a combination of a private and public (but anonymous) social recognition reward. At the same time, Mayer et al. (2018) also implement a soft commitment device - parents set a goal how much time to read to their children-and receive reminders to work toward their reading goal every weekday. These behavioral tools are simultaneously implemented with the recognition rewards and jointly increase the time parents spend reading to their children by one standard deviation compared to parents receiving "placebo" information only. Unfortunately, the experimental design does not allow to disentangle the effect of the social recognition incentive from the soft commitment device and the reminders.

Evidence on the effectiveness of non-monetary incentives for teachers is extremely scarce, despite the fact that in many institutional settings teachers are legally not allowed to accept financial incentives paid by third parties such that only non-monetary incentives could be applied. Studies on non-monetary teacher incentives exclusively report results of teacher surveys on the popularity of various incentives or propose potentially effective nonmonetary incentives, but do not empirically test their effectiveness. Two categories of non-monetary incentives that might be popular among teachers are work avoidance and social recognition incentives. For example, Jacobson and Kennedy (1992) report on deferred salary leave plans in Canada, this is, teachers are allowed to defer a portion of their salary each year to self-fund a leave of absence. In Kobakhidze (2010), teachers' proposals for non-monetary incentives include the pendant to mastery goal incentives to students such as free textbooks, free or discounted professional development literature and training, free classroom materials, financing of extracurriculum activities (e.g., excursions), and classroom technologies (e.g., computers and projectors) as well as social recognition incentives such as "best teacher" or "teacher of the year" awards, greetings on special occasions (e.g., Teacher's Day), moral support from school principals, oral praise and encouragement from the school administration, changes in societal attitudes toward teachers, raising the prestige of teachers, and organizing special events for teachers. Vaillant and Rossel (2012) discuss teachers' status and their public recognition as an important source of teacher motivation and present initiatives in Latin America that seek to raise the status and prestige of the teaching profession. These initiatives award innovative projects, outstanding teachers or classroom activities in a public ceremony which is covered by the most important media of the country and

\footnotetext{
${ }^{7}$ There is a growing body of literature which does not use non-monetary incentives as per our definition but uses behaviorally informed interventions to get parents involved in their children's education. In particular, sending parents text messages with information about their children's performance and behavior in school seems to be a cost-effective and easy to implement way to enhance educational outcomes (Bergman, 2017; Bergman and Chan, 2017; Cunha et al., 2017; Rogers and Feller, 2018; Berlinski et al., 2017).
} 
often combined with monetary incentives such as prizes. Vegas and Umansky (2005) and Chapman et al. (1993) are two further studies that propose social recognition incentives to motivate teachers.

Despite many ideas on their design, there is a striking lack of knowledge concerning the effectiveness of non-monetary incentives for parents and teachers in raising students' educational attainment. In principle, we consider them an equally promising tool as non-monetary incentives for students and see a strong demand for future research.

\section{Discussion and conclusion}

In this paper, we have focused on the design and effectiveness of monetary and non-monetary incentive schemes in education. Regarding monetary incentives, we report results on two design features which have received rather little attention to date: the sensitivity to cash size and the recipient of the reward. While increasing the cash size of the reward does not seem to impact educational outcomes of university students, there is evidence that younger and/or more disadvantaged students seem to respond stronger to higher monetary incentives (Levitt et al., 2016a). Moreover, monetary incentives work equally well for students, parents, and teachers; this is, the recipient of a financial reward of a given size does not make a difference for its effect on students' educational outcomes. Aligning incentives by providing simultaneous monetary incentives to students, parents, and teachers tends to increase their effect sizes beyond those of individual incentives.

During recent years, non-monetary incentives to motivate students have received increasing attention due to their potential cost-effectiveness and higher acceptance among teachers and parents. With respect to nonmonetary incentives, we synthesize the existing literature by the type of incentive and shed light on students' valuation and selection of rewards. We propose to broadly differentiate between two categories of non-monetary incentives: (i) tangible incentives and (ii) granting rights and privileges. So far, tangible non-monetary incentives have been mainly applied in low stakes testing environments among younger students and have produced either no or positive impacts on educational outcomes. In contrast, incentives of the category granting rights and privileges have largely been tested among older students in high stakes environments. These types of incentives, among them bonus points for the next exam and assessment weighting, have been found to be effective in raising students' performance.

An integral part of non-monetary incentives to effectively raise educational attainment or modify students' behavior in class is their ability to induce value for their recipient, typically the students. The aforementioned studies provide first insights in identifying students' valuation for different types of non-monetary incentives. Future research on non-monetary incentives in education should expand this knowledge by reporting on which grounds researchers have chosen certain incentives, by offering students a choice among various incentives to learn which incentives students value most, and by documenting that more highly valued incentives are more effective. The ultimate aim should be to equip teachers with a broad set—a "toolbox"- of effective incentives tailored to the respective target group, taking into account students' age, gender, ability, intrinsic motivation, and family background, for example. As Levitt et al. (2016a) acknowledge, we also need a better understanding whether the same incentives offered on a regular basis maintain their motivational power and thus can be used 
to promote sustained effort provision, habit formation, learning, and educational attainment in the long run. With the knowledge of a "toolbox" of effective incentives, teachers could possibly alternate the incentive scheme which might be more effective than using always the same incentive if rewards are paid repeatedly.

In the attempt to identify new and effective non-monetary incentives, "Induced Value Theory" (Smith, 1976) can give guidance in choosing incentives which are worth testing in the field. According to "Induced Value Theory", the experimenter achieves control over agents' characteristics if the incentive ("reward medium") satisfies three conditions (Friedman and Sunder, 1994): monotonicity, salience, and dominance. That is, incentives should be chosen such that (i) individuals prefer more of the reward medium to less, and do not become satiated (monotonicity), (ii) the reward depends on individuals' actions as defined by the institutional rules that the individual understands (salience), and (iii) changes in individuals' utility from the experiment come predominantly from the reward medium and other influences are negligible (dominance). ${ }^{8}$

While dominance is hard to fulfil in educational settings, researchers should seek for non-monetary incentives that satisfy salience and monotonicity. In particular, dominance may not be met if students are intrinsically motivated to perform well, effectively pressurized by their parents, and/or aware of the high returns to education. Additionally, students likely care about the rewards earned by their peers and experimental procedures cannot always be designed to make it impossible for students to learn about others' rewards. Moreover, dominance could be violated by experimenter demand effects that can potentially arise if researchers are present in the classroom to explain the experimental procedures. ${ }^{9}$ In contrast, salience is usually fulfilled as the conditions to receive the reward can be clearly communicated: i.e., the receipt of incentives typically depends on measures of educational performance or educational inputs that are straightforward to understand for students. For many types of non-monetary incentives, it is less clear whether monotonicity is met or not, e.g., whether students become satiated after receiving the second or third trophy, certificate, or letter to the parents. Bonus points for the next exam clearly fulfil salience and monotonicity and the predominantly positive results of this incentive on students' performance indicate that they induce value to students. Another incentive for younger students which could satisfy salience and monotonicity, but has not yet been tested in studies that aim at raising educational attainment are golden toy coins. Two recent papers provide evidence that golden toy coins induce value to elementary school children (Hermes et al., 2018; Schunk et al., 2017).

\section{Acknowledgments}

We thank Laura Breitkopf and Daniel Kamhöfer for helpful comments on an earlier version of this paper.

\footnotetext{
${ }^{8}$ Friedman and Sunder (1994) give the following intuition for the three features: “...the experimenter can freely choose any relationship between intrinsically worthless objects and the reward medium. As long as he can explain the relationship clearly to the subjects (salience) and subjects are motivated by the reward medium (monotonicity) and no other influences (dominance), then the experimenter can control subjects' characteristics to implement the chosen relationship in the laboratory".

${ }^{9}$ There is a trade-off between running the experiment by the researcher in order to maintain high levels of control over the experiment and delegating the administration of the experiment to teachers to maintain the natural class environment. An additional reason for delegating the experimental implementation to teachers is to decrease the role of experimenter demand effects in order to aim at satisfying the dominance condition.
} 


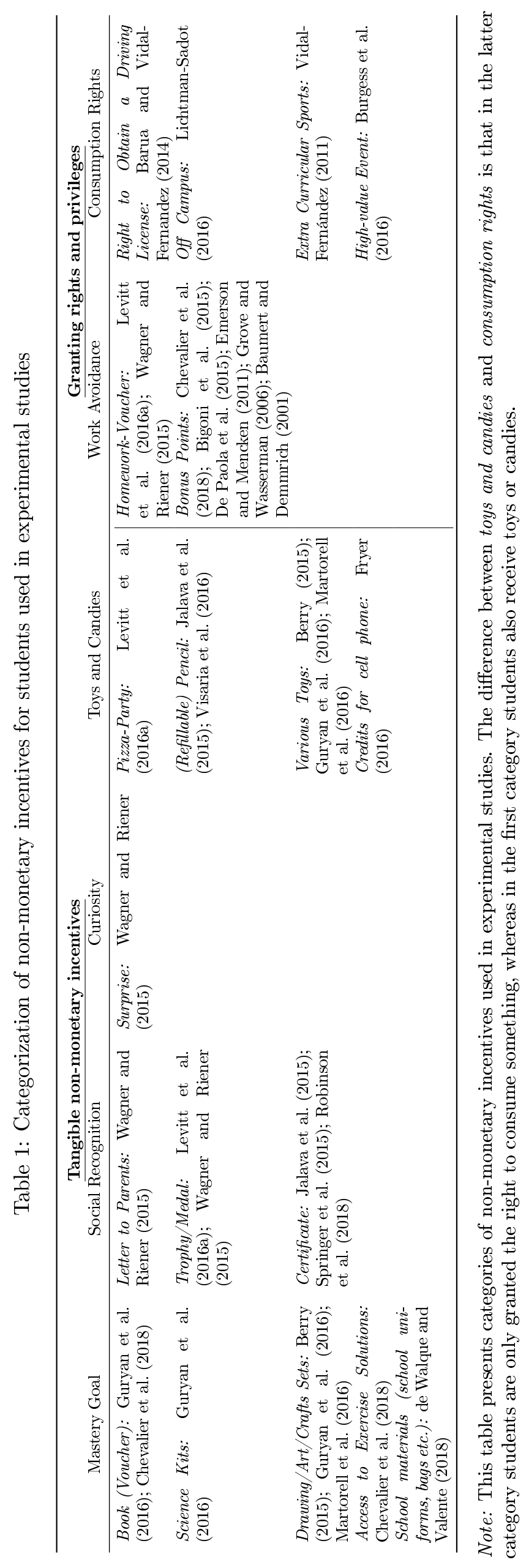




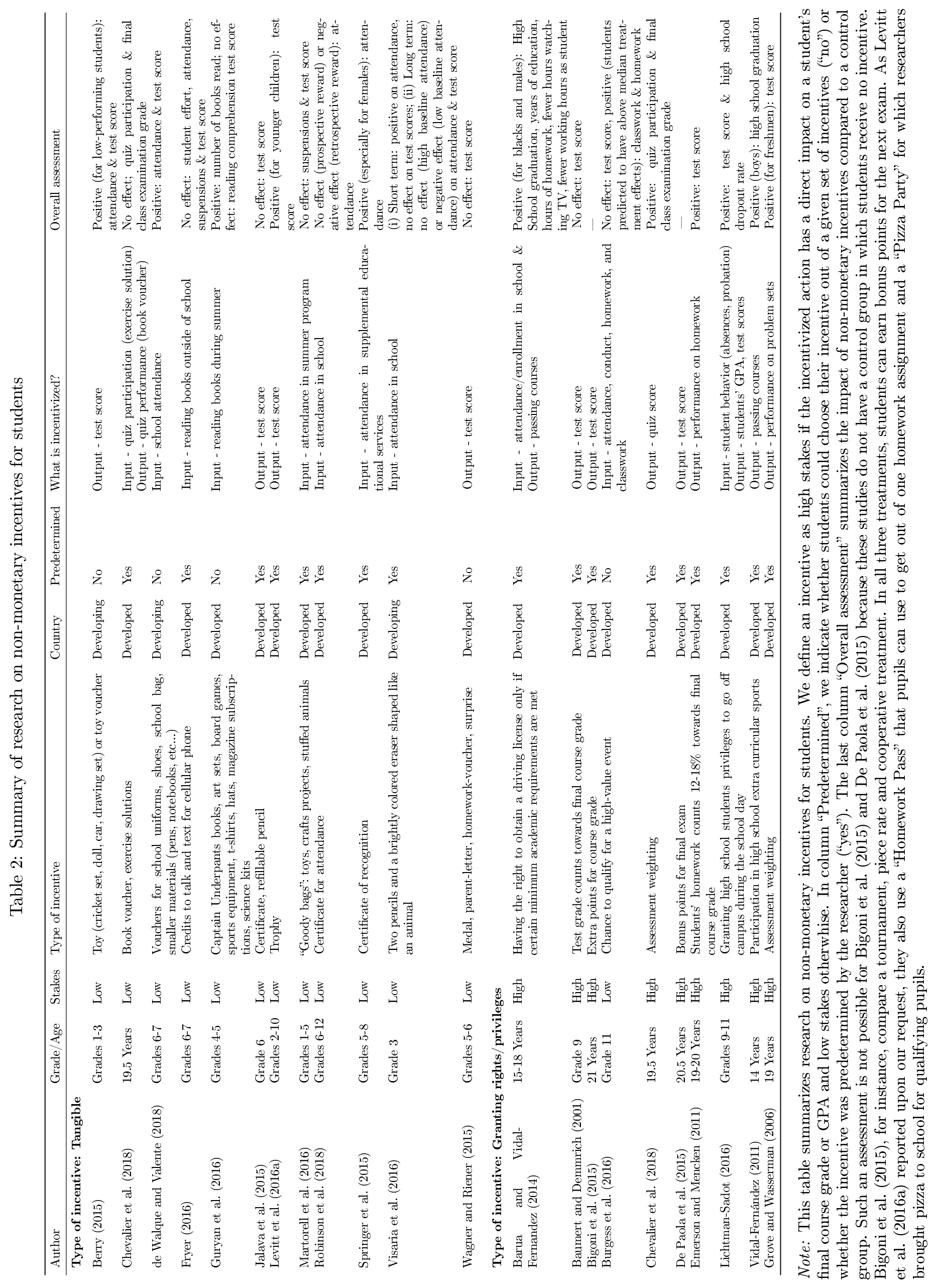


Figure 1: Non-monetary incentives chosen by students in Wagner and Riener (2015)

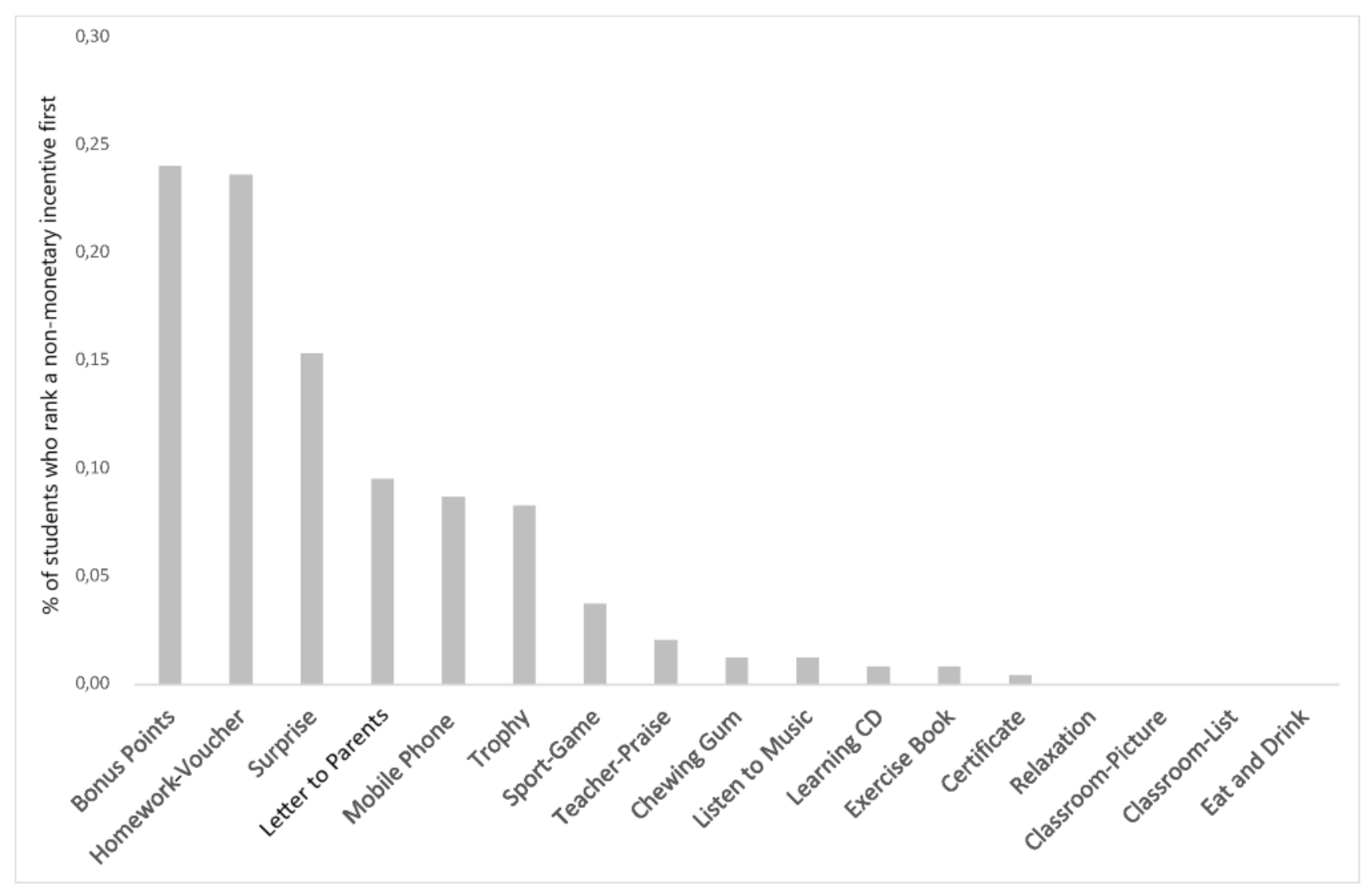

Note: This figure presents the share of students who rank a non-monetary incentive first out of 17 in the survey of Wagner and Riener (2015). The authors distinguish between five categories of non-monetary incentives, with the following specific incentives that are described in detail below: (i) mastery goal incentives - exercise book and learning CD; (ii) social recognition incentives - teacher-praise, classroom-picture, letter to parents, trophy, and certificate; (iii) curiosity incentive - getting a small surprise reward; (iv) work avoidance incentive - bonus points and homework-voucher; (v) consumption rights incentives - chewing gum, listen to music, eat and drink, mobile phone, relaxation, and sport-game.

Exercise Book: receiving a booklet with mathematical exercises.

Teacher-Praise: being praised in front of the class.

Letter to the parents: teacher sends a letter to the parents that praises the pupil's performance.

Surprise: getting a small surprise reward.

Homework-voucher: no homework in math; voucher can be used once until the end of semester.

Chewing Gum: being allowed to eat a chewing gum in one lesson.

Learning $C D$ : receiving a $C D$ with mathematical games.

Classroom-Picture: picture of the pupil who could improve his/her test score is hung up in the classroom.

Trophy: getting a small medal.

Relaxation: relaxing 5 minutes of one lesson.

Listen to Music: being allowed to listen to music for 5 minutes.

Classroom-List: list of all who could improve their test score is hung up in the classroom.

Certificate: receiving a certificate stating that a test score has improved.

Bonus points: receiving extra points for the next written exam.

Eat and Drink: being allowed to eat and drink during class.

Mobile Phone: being allowed to play 5 minutes with the mobile phone in one lesson.

Sport-Game: determining one game in the sports class. 


\section{References}

Ames, C. (1992). Classrooms: Goals, Structures, and Student Motivation. Journal of Educational Psychology, $84(3): 261-271$.

Angrist, J. and Keueger, A. (1991). Does Compulsory School Attendance Affect Schooling and Earnings? The Quarterly Journal of Economics, 106(4):979 - 1014.

Avvisati, F., Gurgand, M., Guyon, N., and Maurin, E. (2014). Getting Parents Involved: A Field Experiment in Deprived Schools. The Review of Economic Studies, 81(1):57 - 83.

Baird, S., McIntosh, C., and Özler, B. (2011). Cash or Condition? Evidence from a Cash Transfer Experiment. The Quarterly Journal of Economics, 126(4):1709 - 1753.

Barrow, L. and Rouse, C. (2018). Financial Incentives and Educational Investment: The Impact of PerformanceBased Scholarships on Student Time Use. Education Finance and Policy, 13(4):419 - 448.

Barua, R. and Vidal-Fernandez, M. (2014). No Pass No Drive: Education and Allocation of Time. Journal of Human Capital, 8(4):399 - 431.

Baumert, J. and Demmrich, A. (2001). Test Motivation in the Assessment of Student Skills: The Effects of Incentives on Motivation and Performance. European Journal of Psychology of Education, 16(3):441 - 462.

Behrman, J., Parker, S., Todd, P., and Wolpin, K. (2015). Aligning Learning Incentives of Students and Teachers: Results from a Social Experiment in Mexican High Schools. Journal of Political Economy, 123(2):325 - 364.

Bergman, P. (2017). Parent-Child Information Frictions and Human Capital Investment: Evidence from a Field Experiment. Unpublished manuscript.

Bergman, P. and Chan, E. (2017). Leveraging Parents: The Impact of High-Frequency Information on Student Achievement. Unpublished manuscript.

Berlinski, S., Busso, M., Dinkelman, T., and Martinez, C. (2017). Reducing Parent-School Information Gaps and Improving Education Outcomes: Evidence from High Frequency Text Messaging in Chile. Unpublished Manuscript.

Berry, J. (2015). Child Control in Education Decisions: An Evaluation of Targeted Incentives to Learn in India. Journal of Human Resources, 50(4):1051 - 1080.

Bettinger, E. and Slonim, R. (2007). Patience Among Children. Journal of Public Economics, 91(1-2):343 363.

Bigoni, M., Fort, M., Nardotto, M., and Reggiani, T. (2015). Cooperation or Competition? A Field Experiment on Non-Monetary Learning Incentives. The B.E. Journal of Economic Analysis 6 Policy, 15(4):1753 - 1792. 
Black, S., Devereux, P., and Salvanes, K. (2008). Staying in the Classroom and out of the Maternity Ward? The Effect of Compulsory Schooling Laws on Teenage Births. The Economic Journal, 118(530):1025 - 1054 .

Burgess, S., Metcalfe, R., and Sadoff, S. (2016). Understanding the Response to Financial and Non-Financial Incentives in Education: Field Experimental Evidence using High-Stakes Assessments. Technical report, IZA Discussion Paper No. 10284.

Bursztyn, L. and Coffman, L. (2012). The Schooling Decision: Family Preferences, Intergenerational Conflict, and Moral Hazard in the Brazilian Favelas. Journal of Political Economy, 120(3):359 - 397.

Bursztyn, L. and Jensen, R. (2015). How does Peer Pressure Affect Educational Investments? The Quarterly Journal of Economics, 130(3):1329 - 1367.

Chapman, D., Snyder, C., and Burchfield, S. (1993). Teacher Incentives in the Third World. Teaching and Teacher Education, 9(3):301 - 316 .

Chevalier, A., Dolton, P., and Lührmann, M. (2018). "Making It Count": Incentives, Student Effort and Performance. Journal of the Royal Statistical Society: Series A (Statistics in Society), 181:323 - 349.

Cunha, F. and Heckman, J. (2007). The Technology of Skill Formation. The American Economic Review, $97(2): 31-47$.

Cunha, N., Lichand, G., Madeira, R., and Bettinger, E. (2017). What is It About Communicating With Parents? Unpublished manuscript.

De Paola, M., Gioia, F., and Scoppa, V. (2015). Are Females Scared of Competing with Males? Results from a Field Experiment. Economics of Education Review, 48:117 - 128.

De Paola, M., Scoppa, V., and Nisticó, R. (2012). Monetary Incentives and Student Achievement in a Depressed Labor Market: Results from a Randomized Experiment. Journal of Human Capital, 6(1):56 - 85.

de Walque, D. and Valente, C. (2018). Incentivizing School Attendance in the Presence of Parent-Child Information Frictions. Technical report, IZA Discussion Paper No. 11637.

Emerson, T. and Mencken, K. (2011). Homework: To Require or Not? Online Graded Homework and Student Achievement. Perspectives on Economic Education Research, 7(1):20 - 42.

Friedman, D. and Sunder, S. (1994). Experimental Methods: A Primer for Economists. Cambridge University Press.

Fryer, R. (2011). Financial Incentives and Student Achievement: Evidence from Randomized Trials. The Quarterly Journal of Economics, 126(4):1755 - 1798.

Fryer, R. (2016). Information, Non-Financial Incentives, and Student Achievement: Evidence from a Text Messaging Experiment. Journal of Public Economics, 144:109 - 121. 
Fryer, R., Devi, T., and Holden, R. (2017). Vertical versus Horizontal Incentives in Education: Evidence from Randomized Trials. Technical report, National Bureau of Economic Research Working Paper 17752.

Gneezy, U., Meier, S., and Rey-Biel, P. (2011). When and Why Incentives (Don't) Work to Modify Behavior. The Journal of Economic Perspectives, 25(4):191 - 209.

Grove, W. and Wasserman, T. (2006). Incentives and Student Learning: A Natural Experiment with Economics Problem Sets. The American Economic Review, 96(2):447 - 452.

Guryan, J., Kim, J., and Park, K. (2016). Motivation and Incentives in Education: Evidence from a Summer Reading Experiment. Economics of Education Review, 55:1 - 20.

Hanushek, E. and Wößmann, L. (2012). Do Better Schools Lead to More Growth? Cognitive Skills, Economic Outcomes, and Causation. Journal of Economic Growth, 17(4):267 - 321.

Hermes, H., Hett, F., Mechtel, M., Schmidt, F., Schunk, D., and Wagner, V. (2018). Do Children Cooperate Conditionally? Adapting the Strategy Method for First-Graders. Technical report, JGU Discussion Paper 1803.

Jacobson, S. and Kennedy, S. (1992). Deferred Salary Leaves in Education: A Canadian Alternative to Reductions in the Teaching Work Force. Educational Evaluation and Policy Analysis, 14(1):83 - 87.

Jalava, N., Joensen, J., and Pellas, E. (2015). Grades and Rank: Impacts of Non-Financial Incentives on Test Performance. Journal of Economic Behavior \& Organization, 115:161 - 196.

Kobakhidze, M. (2010). Teacher Incentives and the Future of Merit-Based Pay in Georgia. European Education, $42(3): 68-89$.

Leuven, E., Oosterbeek, H., and Klaauw, B. (2010). The Effect of Financial Rewards on Sudents' Achievement: Evidence from a Randomized Experiment. Journal of the European Economic Association, 8(6):1243 - 1265.

Levitt, S., List, J., Neckermann, S., and Sadoff, S. (2016a). The Behavioralist Goes to School: Leveraging Behavioral Economics to Improve Educational Performance. American Economic Journal: Economic Policy, $8(4): 183-219$.

Levitt, S., List, J., and Sadoff, S. (2016b). The Effect of Performance-Based Incentives on Educational Achievement: Evidence from a Randomized Experiment. Technical report, National Bureau of Economic Research Working Paper 22107.

Lichtman-Sadot, S. (2016). Improving Academic Performance through Conditional Benefits: Open/Closed Campus Policies in High School and Student Outcomes. Economics of Education Review, 54:95 - 112.

List, J., Livingston, J., and Neckermann, S. (2018). Do financial incentives crowd out intrinsic motivation to perform on standardized tests? Economics of Education Review, 66:125 - 136. 
Lleras-Muney, A. (2005). The Relationship between Education and Adult Mortality in the United States. The Review of Economic Studies, 72(1):189 - 221.

Lochner, L. and Moretti, E. (2004). The Effect of Education on Crime: Evidence from Prison Inmates, Arrests, and Self-Reports. The American Economic Review, 94(1):155 - 189.

Martorell, P., Miller, T., Santibanez, L., and Augustine, C. (2016). Can Incentives for Parents and Students Change Educational Inputs? Experimental Evidence from Summer School. Economics of Education Review, $50: 113-126$.

Mayer, S., Kalil, A., Oreopoulos, P., and Gallegos, S. (2018). Using Behavioral Insights to Increase Parental Engagement: The Parents and Children Together Intervention. Journal of Human Resources.

Milligan, K., Moretti, E., and Oreopoulos, P. (2004). Does Education Improve Citizenship? Evidence from the United States and the United Kingdom. Journal of Public Economics, 88(9-10):1667 - 1695.

Oreopoulos, P. (2007). Do Dropouts Drop out Too Soon? Wealth, Health and Happiness from Compulsory Schooling. Journal of Public Economics, 91(11):2213 - 2229.

Robinson, C., Gallus, J., Lee, M., and Rogers, T. (2018). The Demotivating Effect (and Unintended Message) of Retrospective Awards. Faculty Reseach Working Paper Series RWP18-020, Harvard Kennedy School.

Rogers, T. and Feller, A. (2018). Reducing Student Absences at Scale by Targeting Parents' Misbeliefs. Nature Human Behavior, 2:335 - 342 .

Sadoff, S. (2014). The Role of Experimentation in Education Policy. Oxford Review of Economic Policy, $30(4): 597-620$.

Schunk, D., Berger, E., Hermes, H., Winkel, K., and Fehr, E. (2017). The KIDS-WIN-Study: Design of a Working Memory Training Intervention in Primary Schools. Unpublished manuscript.

Smith, V. (1976). Experimental Economics: Induced Value Theory. The American Economic Review, 66(2):274 -279 .

Springer, M., Rosenquist, B., and Swain, W. (2015). Monetary and Nonmonetary Student Incentives for Tutoring Services: A Randomized Controlled Trial. Journal of Research on Educational Effectiveness, 8(4):453 - 474 .

Vaillant, D. and Rossel, C. (2012). The Recognition of Effective Teaching in Latin America: Awards to Excellence. Teacher Development, 16(1):89 - 110 .

Vegas, E. and Umansky, I. (2005). Improving Teaching and Learning through Effective Incentives: What Can We Learn from Education Reforms in Latin America? Washington D.C.: World Bank.

Vidal-Fernández, M. (2011). The Effect of Minimum Academic Requirements to Participate in Sports on High School Graduation. The BE Journal of Economic Analysis 6 Policy, 11(1). 
Visaria, S., Dehejia, R., Chao, M., and Mukhopadhyay, A. (2016). Unintended Consequences of Rewards for Student Attendance: Results from a Field Experiment in Indian Classrooms. Economics of Education Review, $54: 173-184$.

Wagner, V. and Riener, G. (2015). Peers or Parents? On Non-Monetary Incentives in Schools. Technical report, DICE Discussion Paper 203.

\section{Further Reading}

Allan, B.M. and Fryer, R.G. (2011). The Power and Pitfalls of Education Incentives. Policy Paper, Hamilton Project.

Angrist, J. D., Lang, D., Oreopoulos, P. (2009). Incentives and Services for College Achievement: Evidence from a Randomized Trial. American Economic Journal: Applied Economics, 1 (1): 1 - 29.

Angrist, J. D., Lavy, L. (2009). The Effects of High Stakes High School Achievement Awards: Evidence from a Randomized Trial. The American Economic Review, 99 (4): 1384 - 1414.

Angrist, J. D., Oreopoulos, P., Williams, T. (2014). When Opportunity Knocks, Who Answers? New Evidence on College Achievement Awards. Journal of Human Resources, 49 (3): 572 - 610.

Bettinger, E. P. (2012). Paying to Learn: The Effect of Financial Incentives on Elementary School Test Scores. Review of Economics and Statistics, 94 (3): 686 - 698.

Bettinger, E. P., Long, B. T., Oreopoulos, P., Sanbonmatsu, L. (2012). The Role of Application Assistance and Information in College Decisions: Results from the H\&R Block Fafsa Experiment. The Quarterly Journal of Economics, 127 (3): $1205-1242$.

Bishop, J. (2006). Drinking from the Fountain of Knowledge: Student Incentive to Study and Learn - Externalities, Information Problems and Peer Pressure. In Handbook of the Economics of Education, Vol. 2, edited by Eric A. Hanushek, Finis Welch. Amsterdam: North Holland: 909 - 944.

Damgaard, M. T., Nielsen, H. S. (2018). Nudging in Education. Economics of Education Review, 64: 313 342 .

Duflo, E., Dupas, P., Kremer, M. (2015). School Governance, Teacher Incentives, and Pupil - Teacher Ratios: Experimental Evidence from Kenyan Primary Schools. Journal of Public Economics, 123: 92 - 110.

Fryer, R. G. (2013). Teacher Incentives and Student Achievement: Evidence from New York City Public Schools. Journal of Labor Economics, 31 (2): 373 - 427.

Fryer, R. G., Levitt, S. D., List, J., Sadoff, S. (2012). Enhancing the Efficacy of Teacher Incentives through Loss Aversion: A Field Experiment. Working Paper 18237, National Bureau of Economic Research.

Glewwe, P., Ilias, N., Kremer, M. (2010). Teacher Incentives. American Economic Journal: Applied Economics, $2(3): 205-227$.

Koch, A., Nafziger, J., Nielsen, H.S. (2015). Behavioral Economics of Education. Journal of Economic Behavior E) Organization, 115: $3-17$.

Lavecchia, A. M., Liu, H., Oreopoulos, P. (2015). Behavioral Economics of Education: Progress and Possibilities. In Handbook of the Economics of Education, Vol. 5, edited by Eric A. Hanushek, Stephen Machin, Ludger 
Woessmann. Amsterdam: North Holland: $1-74$.

Lavy, V. (2002). Evaluating the Effect of Teachers' Group Performance Incentives on Pupil Achievement. Journal of Political Economy, 110 (6): 1286 - 1317.

Neal, D. (2011). The Design of Performance Pay in Education. In Handbook of the Economics of Education, Vol. 4, edited by Eric A. Hanushek, Stephen Machin, Ludger Woessmann. Amsterdam: North Holland: 495 550 .

Oswald, Y., Backes-Gellner, U. (2014). Learning for a Bonus: How Financial Incentives Interact with Preferences. Journal of Public Economics, 118: $52-61$.

Woessmann, L. (2011). Cross-Country Evidence on Teacher Performance Pay. Economics of Education Review, $30(3): 404-418$. 